\title{
Investigations on Directed Infrared Countermeasures Risks to Fighter Aircraft Pilots
}

\author{
Lester de Abreu Faria1, Luciano Barbosa Magalhães², Roberto d'Amore1
}

\begin{abstract}
Directed Infrared Countermeasures (DIRCM) are used to protect aircrafts against missiles with infrared (IR) guidance. They are employed by military and civilian aircrafts, drawing away the guidance system of a missile as it attempts to lock onto the IR signature of the turbines. Unfortunately, the protection provided by these devices generates risks and challenges that must be overcome. In this paper, investigations on DIRCM risks to fighter aircraft pilots are carried out. Different kinds of lasers employed in actual DIRCMs are analyzed and the results show that, depending on their frequency (wavelength), damages can occur up to a distance of $4.8 \mathrm{~km}$. The transmittance through the canopy of an F-5 fighter aircraft is evaluated and its effects on the IR propagation are predicted by the use of software called Counter-Measurements in PYTHON (CMePy). Results show that, even when there are interfaces between the pilot and the source of radiation, damages can occur, showing the importance of this investigation to the right understanding of this subject and future mitigations.
\end{abstract}

KEYWORDS: Aerospace, Safety, Defense systems, Laser, DIRCM, Infrared.

\section{CONTEXTUALIZATION}

Since September $11^{\text {th }}, 2001$, the entire world, but specially the USA, focuses its attention on the use of man portable air defense system (MANPADS) as the main terrorist's weapon for striking civilian and military aircrafts. Today, there are approximately 500,000 shoulder-fired missiles in military arsenals around the world, while there are from 5,000 to 150,000 in the hands of up to 30 non-state organizations, according to a report by the Congressional Research Service (CRS) (Bolkcom et al., 2003). An analysis provided by the CRS indicates that, in the last 30 years, there were, at least, 35 civilian aircraft attacks through the use of MANPADS, of which 24 were shot down (Laurenzo, 2005; Nakagawara and Montgomery, 2008).

Since then, there has been a trend not only for military but also for civilian aircrafts to be equipped with some kind of countermeasure that can draw away the guidance system of a missile as it attempts to lock onto the infrared (IR) signature of the turbines of the aircraft.

Flare-based C-MANPAD systems were a main solution for military aircrafts, but the fear of collateral damage from these kinds of countermeasures, should the flares be deployed by mistake, makes it non-optimum. Therefore, some alternative countermeasure systems were developed to be employed as infrared countermeasures (IRCM). These systems disrupt the guidance systems of surface-to-air missiles (SAM), using multiple-wavelength lasers that emit radiation in the IR portion of the electromagnetic spectrum. Unfortunately, new

\footnotetext{
三 1.Instituto Tecnológico de Aeronáutica - São José dos Campos/SP - Brazil 2.Comando-Geral de Operações Aéreas - Rio de Janeiro/RJ - Brazil Author for correspondence: Lester de Abreu Faria | Praça Marechal Eduardo Gomes, 50 - Vila das Acácias | CEP 12.228-900 São José dos Campos/SP - Brazil | Email: lester@ita.br

Received: $12 / 07 / 13$ | Accepted: 30/08/13
} 
systems generate new risks and new challenges to scientific and medical areas that must be overcome.

IR emissions from these laser systems can be hazardous to ocular tissues and skin under certain circumstances. Depending on factors like energy delivered per unit area, exposure time, and wavelength, several damages can occur.

The major danger in IR emissions to the human vision is the lack of response of the ocular system to this type of radiation. The human eye can detect only wavelengths in the visible optical range and, in the case of the IR radiation, it is only noticed when some kind of damage has already happened (Nakagawara and Montgomery, 2008).

Figure 1 indicates which wavelengths are mainly absorbed in the different parts of the eye: the cornea, the lens, or the retina (Brunetaud and Hill, 2012).

Concerning the IR wavelengths, if the source is within the nominal ocular hazard distance (NOHD) of the pilot, near-IR (NIR) (780-1400 nm) laser radiation may damage the retina, while middle-IR (MIR) and far-IR laser radiations $(>1400 \mathrm{~nm})$ can injure the cornea and, to a lesser extent, the crystalline lens.

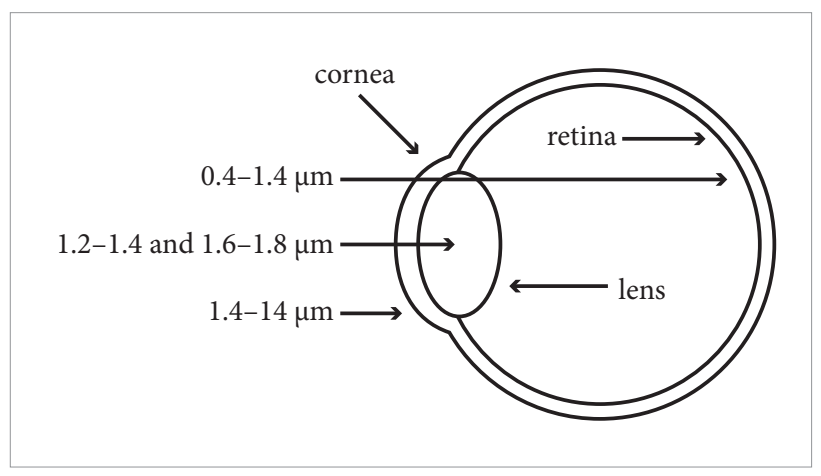

Figure 1. Parts of the eye at risk from different wavelengths (adapted from Brunetaud and Hill, 2012).
On the other hand, although skin burns are not generally very serious if a person is able to feel the damage and leave the radiation area, it becomes much more serious if people cannot react to the exposure, as the situation where a pilot is engaged in a combat arena (Brunetaud and Hill, 2012).

Table 1 demonstrates the potential injuries resulting from the excessive exposure to visible and IR radiation.

Excessive exposure to optical radiation in different ranges is currently a concern to industrial hygienists, safety engineers, and public health officials in many developed countries around the world for their potential hazard to health and safety (Nakagawara and Montgomery, 2008). In the literature, a lot of information and works can be found about dangers associated with exposure to excessive levels of visible and UV radiation in the USA National Airspace System (NAS) (Diffey and Roscoe, 1990; Caidin, 1992; West et al., 1998) and other airspace systems (NASA, 1998; Wisegeek, 1999; Setlow, 2003). There are, as well, many studies on the transmittance of polycarbonate in different ranges of IR. However, only a few works conjugate both information and deal with the potential hazards to human health from the exposure to high levels of IR radiation, in free space or through an additional interface (Nakagawara and Montgomery, 2008). Above all, such kind of research has not yet been performed in Brazil, leading to a lack of information on professional diseases and impacting the performance of the pilots. The same results found in this work can be expandable to the "occupational health and safety", for all of those who work with laser emissions.

This paper shows a study made by the Electronic Warfare Laboratory (LAB-GE), at Technological Institute of Aeronautics (ITA), Brazil, concerning to the IR and visible radiation risks to the pilot's health and the protection provided by aircraft canopies. Transmittance properties of a fighter aircraft canopy from the visible to the IR range

Table 1. Potential injuries from excessive exposure to visible and infrared radiation.

\begin{tabular}{|c|c|c|c|c|}
\hline Spectral band & Visible & NIR & MIR & FIR \\
\hline Wavelenght (nm) & $380-780$ & $780-1400$ & $1400-3000$ & $3000-10^{6}$ \\
\hline \multirow{4}{*}{ Potential injury } & \multicolumn{2}{|c|}{ Retinal burns } & \multicolumn{2}{|c|}{ Corneal burns } \\
\hline & \multicolumn{3}{|c|}{ Cataracts } & \\
\hline & $\begin{array}{l}\text { Color and night } \\
\text { vision degradation }\end{array}$ & & & \\
\hline & \multicolumn{4}{|c|}{ Thermal skin burns } \\
\hline
\end{tabular}


(670-12000 $\mathrm{nm})$ are presented. Further discussion on the electromagnetic spectrum leads to a "big picture" of the environment where the pilot operates and the risks to which he is submitted.

\section{DIRECTED INFRARED COUNTERMEASURES}

Directed Infrared Countermeasures (DIRCM) is used to protect aircraft against missiles with IR guidance, especially the portable ones that can be shoulder-launched (also known as MANPADS). Its operation is given in conjunction with missile approach warning system (MAWS), which is responsible for the detection of an approaching missile, determining if it is a threat to the aircraft, and providing the approaching direction of threat to DIRCM. This signal activates the laser transmitter, which will engage the threat and transmit energy modulated beams to deflect it from the aircraft.

Those equipments can be classified in two kinds of systems: directional and non-directional. Considering this work, we will focus on the directional DIRCM, once they are the most advanced and the most efficient ones recently in use.

The directional DIRCM operates by emitting radiation beams with small angular apertures, as lasers. This feature leads to low operation power and low response time. Besides that, they show spectral and spatial power densities much higher than any other typical source, due to the low divergence found in the optical laser beam (order of milliradians). Its main disadvantage is the need of using turrets to direct the beam emission against the missile, requiring high pointing accuracy and integrated communication with the MAWS An example of this kind of equipment is AN/AAQ-24(V) NEMESIS, from Northrop-Grumman (GlobalSecurity.org. 2011), which is shown in Fig. 2.

There are also multi-spectral DIRCMs, which can handle multiple threats fired from any direction, and are adaptable to threat changes. These equipments are able to operate in different IR bands (Elbit Systems of America , 1999).

In order to analyze the emission of a directional DIRCM, it must be considered the main characteristics of a laser beam, such as: high spectral and spatial power density, high directivity, low operating power, low bandwidth beam, and pulse operation.

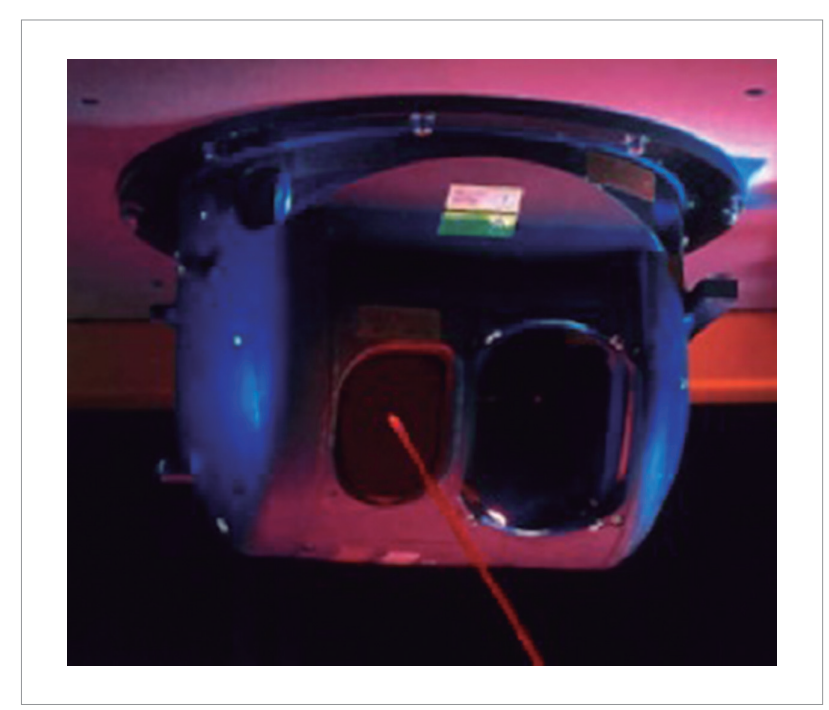

Figure 2. $A N / A A Q-24(V)$ NEMESIS, from Northrop-Grumman.

\section{GENERAL CONSIDERATIONS}

Given the possibility of physiological tissue damage, a study was performed considering the potential effects that IR countermeasure equipment radiation could cause not only to human vision but also to human skin. Therefore, initially, some actual DIRCM data were collected from the literature and their potential risks to human health were dimensioned. After that, the transmittance of the canopy of an F-5 fighter aircraft was measured from visible to IR band, since this structure can be perceived as a filter, or a first barrier, between the emitting source and the pilot. The measurements were performed in LAB-GE/ITA. In order to predict the potential risks before and after the insertion of interfaces (canopy or any others), it was developed and used a software called Counter-Measurements in PYTHON (CMePy), which calculates the optical power that reaches the eye, or the skin, of a pilot, helping us to dimension the problem.

An aircraft canopy is the transparent enclosure over the cockpit. Its main function is to provide a weatherproof and reasonably quiet environment for the aircraft's occupants, protecting them during flight. The canopy must be as aerodynamically shaped as possible to minimize drag and as transparent as possible to improve the outside visibility (AS 2211, 1991; Nakagawara and Montgomery, 2008). A high-performance aircraft's 
canopy is vital not only for the previous features but also for the enhancing and protecting of the pilot's vision. High-performance aircrafts from the Brazilian Air Force use polycarbonate (plastic) as canopy compound. The transmittance of a canopy compound can affect pilot's visual performance while providing protection from harmful electromagnetic radiation.

On the other hand, transmittance may be defined as the ratio of the total radiant flux that is transmitted, to that incident on the surface of the aircraft canopy. Higher is the ratio, higher is the transmittance.

\section{MEASUREMENTS AND EXPERIMENTAL RESULTS}

Once it was understood how the energy generated by the DIRCM can interact with the human eye, it was necessary to perform some transmittance measurements of aircraft canopies, in order to figure out how radiation is transmitted through these interfaces.

To perform this, it was collected random samples of the material used in the canopy of the F-5 fighter aircraft. The measurements were performed using a Spectrum 400 spectrometer, manufactured by PerkinElmer. This is a device that relies on the concepts of the Michelson interferometer to perform the measurement of transmittance of the sample at the wavelengths of interest. It allows measurements in the band from 0.67 to $18 \mu \mathrm{m}$.

The measurements were conducted in a controlled environment in terms of temperature $\left(23 \pm 0.1^{\circ} \mathrm{C}\right)$ and relative humidity ( $65 \pm 1 \%$ ), for wavelengths from 0.67 to $12 \mu \mathrm{m}$. The samples were placed inside the spectrometer using a support, which was set an incidence angle of $90^{\circ}$. Figure 3 shows a sample being measured in the spectrometer.

The measurement results are calculated, as a function of wavelength, using the ratio between the intensity of radiation that reaches the detector and the one emitted by the source. A correction factor is applied considering the background emission. The actual result of the measurement performed is shown in Fig. 4.

As seen in Fig. 4, the canopy presents a high transmittance, from the initial wavelength $(0.67 \mu \mathrm{m})$ up to $1.6 \mu \mathrm{m}$ with some absorption valleys around 1.19 and $1.4 \mu \mathrm{m}$.

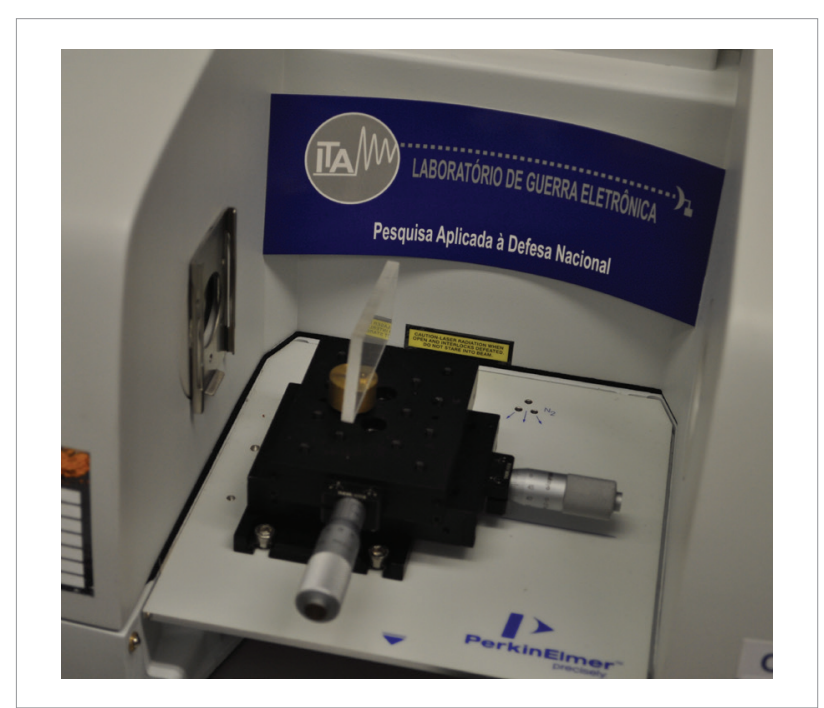

Figure 3. Canopy sample inside the spectrometer in order to perform the measurements.

From $1.6 \mu \mathrm{m}$ on, transmittance drops sharply close to zero, presenting peaks around 1.8 and $2 \mu \mathrm{m}$, showing a transmittance level around $40 \%$. Thereafter, the measured values are almost zero, up to the limit of the measurement, $12 \mu \mathrm{m}$, although the graph is presented only up to $3 \mu \mathrm{m}$. We must highlight the presence of valleys in $1.19,1.4$, and $1.9 \mu \mathrm{m}$, which correspond to the wavelengths where a high absorption by the water molecules in the air occur (Hudson, 1969). On the other hand, it is estimated that the observed absorption at $1.7 \mu \mathrm{m}$ refers to the polycarbonate, once, synthesized from hydrocarbons, it will present absorption bands around the wavelengths of $1.68,1.70,1.72$, and $1.78 \mu \mathrm{m}$ (Araújo and Kawano, 2001).

The results presented in Fig. 4 show that there is no transmission through the canopy for emission whose wavelengths are above $2.2 \mu \mathrm{m}$ (except for a small region around $2.6 \mu \mathrm{m}$ ), because these wavelengths are completely absorbed or reflected by the material. This result agrees with other ones found in the literature (Nakagawara and Montgomery, 2008). Therefore, the canopy shows high effectiveness against directional DIRCM MIR emissions. However, if the DIRCM is multi-spectral and presents spectral components in the NIR, the canopy does not serve as protection, since the transmittance is around $90 \%$, and only $10 \%$ of the incident power is reflected or absorbed by it. Based on these results, a theoretical analysis was performed, focusing on possible damages to the pilot's health. 


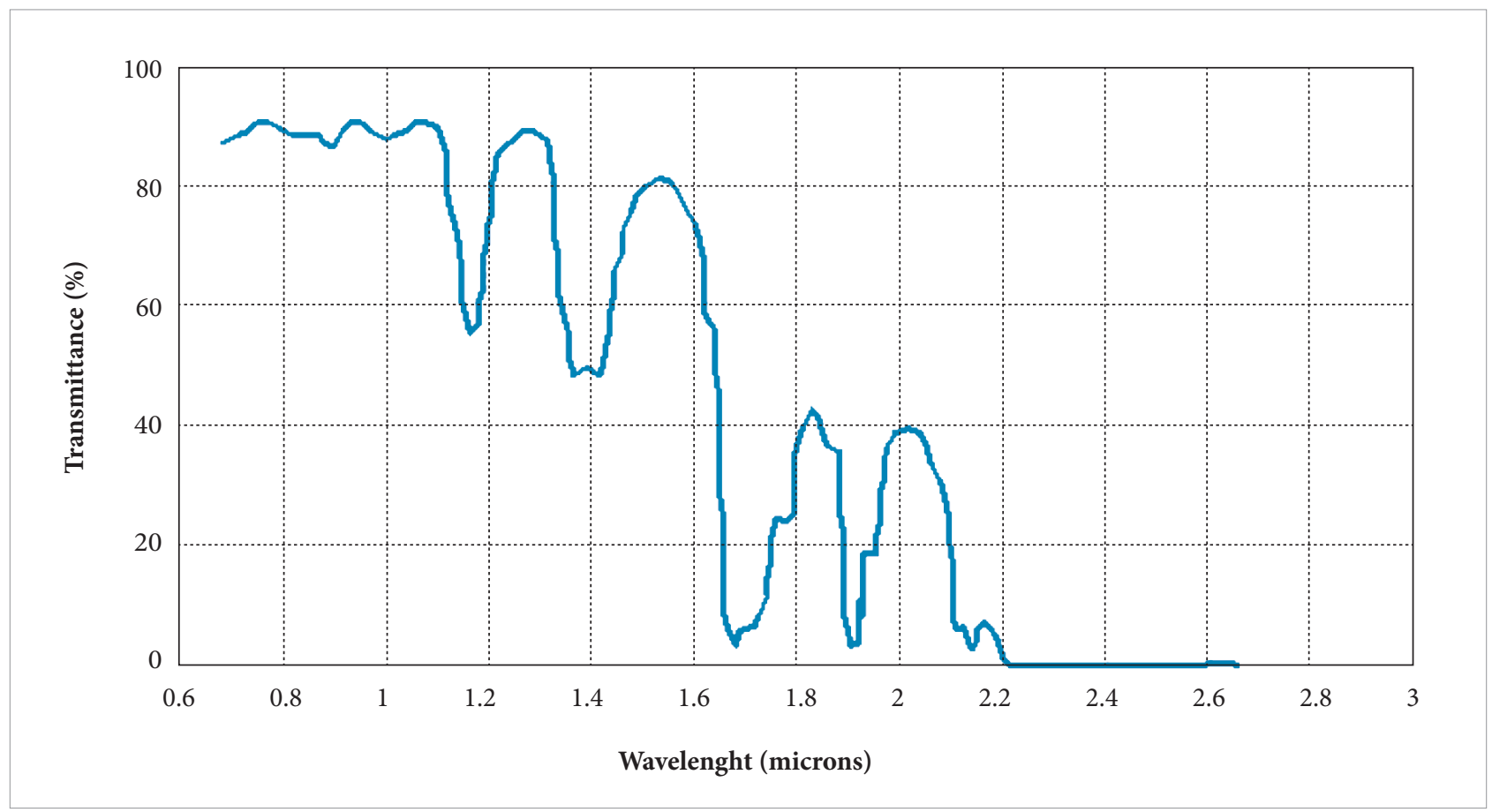

Figure 4. Experimental results of visible, near-infrared, and middle-infrared transmittance.

\section{THEORETICAL ANALYSIS}

Due to the high transmissivity of the canopy in the NIR range, it was made a theoretical analysis of possible damages to the pilot's vision, given the main features of well-known lasers and safety parameters for human vision. Therefore, some definitions are necessary, as shown in AS 2211:

- Maximum permissible exposure (MPE): maximum level of radiation to which human tissue can be exposed without suffering injury or damage immediately after exposure or after some time;

- Nominal ocular hazard distance (NOHD): minimum safety distance where the radiant intensity of the ocular tissue (retina) is considered to be below the level defined as MPE; and

- Nominal skin hazard distance (NSHD): minimum safety distance at which the radiant intensity on the skin is below the level defined as MPE.

Although the aim of this work is to analyze the possible damage to vision, some calculations on the potential damage to the human skin were included, once the procedure for performing both calculations is similar and the used software (CMePy) provides the complete information on them (with appropriate changes in reference tables).

The analysis starts by using the equation that calculates the intensity of a laser beam $\left(\mathrm{W} / \mathrm{m}^{2}\right)$ at a distance $z$ from the laser source, which is given by (Lelek, 2007):

$I=\frac{4 P_{0} \exp (-z \mu)}{\pi(2 w+z \theta)^{2}}$

In Eq. $1, P_{0}$ is the power of the source (in Watts), or eventually the total energy carried by one pulse (in Joules), considering a Gaussian beam; $w$ is the waist of the Gaussian beam $(\mathrm{m})$ at a distance where the beam intensity is $1 / e^{2}$ of $P_{0} ; \theta$ is the divergence of the beam ( $\left.\mathrm{rad}\right) ; \mu$ is the atmospheric absorption (usually neglected) (Nakagawara and Montgomery, 2008); and $z$ is the distance between the source and the target.

Since, for safety reasons, it is necessary to calculate the NOHD of a laser with respect to the retina, variable $z$ should be replaced by NOHD in Eq. 1; while the variable $I$ must be replaced by MPE. Thus, considering the transmittance of 
any interfaces (such as the canopy) as $\tau_{m}$ and a multiplicative factor of 2.5 for non-Gaussian beams, one arrives to (AS 2211; Lelek, 2007):

$N O H D=\frac{\sqrt{\frac{4 P_{0} \tau_{m} 2.5}{\pi M P E}}-2 w}{\theta}$

Equation 2 was applied on data of Table 2, achieving the results presented in Table 3. The calculation of the MPE is required for each one of the lasers. It was obtained by following the instructions and tables provided in AS 2211; Nakagawara and Montgomery (2008), Northwestern University (2012), and Fred Seeper (2012), considering always the most restrictive value of this parameter, as established by the AS 2211. In general, the procedures for the calculation of the MPE can be summarized as follows:

- For a continuous wave (CW) laser source, the wavelength of the CW laser beam, the duration time, and the size of the laser source beam must be determined. By selecting the appropriate MPE table, use the laser wavelength ( $\mathrm{nm}$ ) and exposure time $(t)$ to locate the MPE value or formula on the table and calculate it.

- For a pulsed laser source, the pulse length, the pulse repetition rate, the laser wavelength, the exposition time, and source beam size must be determined. Based on these data, (1) calculate the MPE for a single laser pulse, using the pulse length as the duration time. Then, (2) calculate the MPE for a repeated laser pulse by dividing the MPE for a single pulse by $N^{0.25}$, where " $N$ " is the actual number of pulses. Finally, (3) calculate the single pulse MPE again, using the duration time and divide this result by the number of pulses $(N)$ to determine the average MPE for the pulsed laser source. Choose the smallest of the three values as the MPE for the pulsed laser source.

Besides considering the parameters shown in Table 2 for the calculations of each one of the lasers, the following assumptions were made (Nakagawara and Montgomery, 2008):

Table 2. Lasers technical specifications used in simulations.

\begin{tabular}{|c|c|c|c|c|c|c|c|c|}
\hline Laser * & $\begin{array}{l}\text { Wavelength } \\
\text { [nm] }\end{array}$ & $\begin{array}{l}\text { FRP } \\
{[\mathrm{Hz}]}\end{array}$ & $\begin{array}{l}P_{0} \\
{[W]}\end{array}$ & $\begin{array}{l}\text { Beam divergence } \\
\text { [mrad] }\end{array}$ & $\begin{array}{c}\text { Pulse width } \\
\text { [ns] }\end{array}$ & $\begin{array}{l}\text { Beam waist } \\
\text { [mm] }\end{array}$ & $\begin{array}{c}\text { Exposition time } \\
\text { [s] }\end{array}$ & $\begin{array}{c}\text { Gaussian } \\
\text { beam? }\end{array}$ \\
\hline GaAs & 840 & 15 & $300 \times 10^{-3}$ & 1 & 12 & 0.4 & 10 & No \\
\hline Nd:YAG & 1064 & 15 & $300 \times 10^{-3}$ & 1 & 12 & 0.4 & 10 & No \\
\hline Nd:YAG & 1330 & 15 & $300 \times 10^{-3}$ & 1 & 12 & 0.4 & 10 & No \\
\hline $\mathrm{Cr}^{2+}: \mathrm{CdSe}$ & 2600 & 15 & $300 \times 10^{-3}$ & 1 & 12 & 0.4 & 10 & No \\
\hline $\mathrm{HeNe}$ & 3390 & 15 & $300 \times 10^{-3}$ & 1 & 12 & 0.4 & 10 & No \\
\hline $\mathrm{CO}_{2}$ & 10600 & 15 & $300 \times 10^{-3}$ & 1 & 12 & 0.4 & 10 & No \\
\hline
\end{tabular}

*Nakagawara and Montgomery (2008)

Table 3. Safety distances for the lasers under test.

\begin{tabular}{|c|c|c|c|c|c|}
\hline Laser * & $\begin{array}{l}\text { Wavelength } \\
\text { [nm] }\end{array}$ & $\begin{array}{l}\text { MPE eye } \\
{\left[\mathrm{J} / \mathrm{m}^{2}\right]}\end{array}$ & $\begin{array}{c}\text { MPE skin } \\
{\left[\mathrm{J} / \mathrm{m}^{2}\right]}\end{array}$ & $\begin{array}{c}\text { NOHD } \\
\text { [m] }\end{array}$ & $\begin{array}{c}\text { NSHD } \\
\text { [m] }\end{array}$ \\
\hline GaAs & 840 & $2.72 \times 10^{-3}$ & 108.89 & 4834.98 & 23.38 \\
\hline Nd:YAG & 1064 & $14.29 \times 10^{-3}$ & 285.74 & 2110.10 & 14.13 \\
\hline Nd:YAG & 1330 & $114.30 \times 10^{-3}$ & 285.74 & 745.51 & 14.13 \\
\hline $\mathrm{Cr}^{2+}: \mathrm{CdSe}$ & 2600 & 28.57 & 28.57 & 46.40 & 46.40 \\
\hline $\mathrm{HeNe}$ & 3390 & 28.57 & 28.57 & 46.40 & 46.40 \\
\hline $\mathrm{CO}_{2}$ & 10600 & 28.57 & 28.57 & 46.40 & 46.40 \\
\hline
\end{tabular}

*Nakagawara and Montgomery (2008) 
- Negligible atmospheric attenuation (equals to zero);

- Transmittance of the optical interfaces equal to $100 \%$;

- The beam is stationary during each one of the analysis; and

- Only one wavelength is emitted.

The previous assumptions were established in order to simplify the analysis. Although being slightly different from the ones found in an actual environment, they serve as a basis for the conclusions to which we want to reach.

The results presented in Table 3 were calculated with the aid of a program called CMePy developed specifically for this purpose, in a PYTHON environment. It is able to calculate both the MPE and NOHD for eye and skin in atmosphere transmission, with or without the presence of any interfaces, considering that the spectral transmissivity of that interface is known.

The analysis of Table 3 shows that lasers operating in the NIR (as may be the case for multi-spectral DIRCMs) present a high danger to the pilot's eye, since the calculated NOHD shows that, even at distances of $4834.98 \mathrm{~m}$ (GaAs, $840 \mathrm{~nm}$ ), the laser beam irradiance is sufficient to cause damage to the retina. For higher wavelengths, the danger is reduced, since the NOHD and NSHD are much smaller and highly improbable to occur in actual situations. Although being improbable in an actual flight situation, these data must be considered if a ground test is being conducted. This conclusion leads to the necessity of using specific personal protection equipment (PPE) during the tests.

It is important to mention that the procedure followed for the calculation and analysis of results is the same of that one published by the Laser Institute of America (LIA) under number ANSI Z136.
Once the NOHD and NSHD are known, in free space, it is important to calculate these parameters considering the influence of the canopy, according to Fig. 4, since it works as a filter. Therefore, the values of transmittance shown in Fig. 4 were inserted in Eq. 2 as the variable $\tau_{m}$. The results are shown in Table 4.

The results show that the IR attenuation provided by the canopy reduces NOHD of the three different types of lasers operating in the region of danger to the retina $(<1.4 \mu \mathrm{m})$ in only $10 \%$, in average. On the other hand, for wavelengths above $2.2 \mu \mathrm{m}$, in regions of MIR and FIR, the canopy acts as a perfect filter, protecting the pilot completely, except laser $\mathrm{Cr}^{2+}$ :CdSe $(2600 \mathrm{~nm})$, which, despite of suffering a strong attenuation, still presents some danger, depending on the distance of emission. The same conclusions can be extended to NSHD measurements. However, in this last case, the calculated distances are very low, showing to be highly improbable to occur in practice.

\section{CONCLUSIONS}

In this paper, we presented an investigation on the DIRCM risks to fighter aircraft pilots. Through experimental results and using a computational tool, it was showed that the F-5 fighter aircraft canopy provides only partial protection against IR radiation.

Measurements performed using a spectrometer showed that the average transmittance for canopies in the NIR range $(0.67-1.3 \mu \mathrm{m}$ ) was around $90 \%$ (around $10 \%$ of absorption and reflection of canopy), presenting valleys at 1.19 and $1.4 \mu \mathrm{m}$.

Table 4. Safety distances for lasers when interfaced by the canopy.

\begin{tabular}{|l|c|c|c|c|}
\hline Laser* & $\begin{array}{c}\text { Wavelength } \\
(\mathbf{n m}]\end{array}$ & $\begin{array}{c}\text { NOHD } \\
(\mathbf{m}]\end{array}$ & $\begin{array}{c}\text { NSHD } \\
(\mathbf{m})\end{array}$ & Transmittance \\
\hline GaAs & 840 & 4535.56 & 21.88 & 0.88 \\
\hline $\mathrm{Nd}: \mathrm{YAG}$ & 1064 & 2013.06 & 13.44 & 0.91 \\
\hline $\mathrm{Nd}: \mathrm{YAG}$ & 1330 & 570.09 & 10.61 & 0.60 \\
\hline $\mathrm{Cr}{ }^{2+}: \mathrm{CdSe}$ & 2600 & 5.87 & 5.87 & 0.02 \\
\hline $\mathrm{HeNe}$ & 3390 & $-0.80^{(1)}$ & $-0.80^{(1)}$ & 0.00 \\
\hline $\mathrm{CO}_{2}$ & 10600 & $-0.80^{(1)}$ & $-0.80^{(1)}$ & 0.00 \\
\hline
\end{tabular}

${ }^{(1)}$ Negative values do not have physical meaning and must be considered "O". For these mathematical results, laser is shown to be safe at any distance (AS 2211) *Nakagawara and Montgomery [2008) 
From $1.5 \mu \mathrm{m}$ on, transmittance drops sharply close to zero, presenting two peaks at 1.8 and $2 \mu \mathrm{m}$ (around 40\%). For wavelengths higher than $2.2 \mu \mathrm{m}$, transmittance show to be almost zero.

Due to the high transmissivity in NIR, additional theoretical calculations were performed, which showed that the safety distances for certain lasers operating in this range can reach up to $4.8 \mathrm{~km}$, depending on some parameters of operation. Even with the canopy as an interface, this distance does not seem to be considerably reduced $(\approx 4.5 \mathrm{~km})$.
These results demonstrate that the F-5 canopy offers only limited protection against IR emissions, especially against DIRCMs operating at NIR wavelengths, to which the NOHD can reach more than $4.5 \mathrm{~km}$. In order to complement this work, it is suggested that the same measurements are performed to visors of helmets used by pilots (mandatory item in fighter aircraft), as well as on other kinds of canopies, in order to have a more comprehensive picture of the problem, since different materials with different thicknesses will infer different spectral transmittances to the canopies

\section{REFERENCES}

Araújo, S.C. and Kawano, Y., 2001, "Espectro vibracional no infravermelho próximo dos polímeros poliestireno, Poli (Metacrilato de Metila) e Policarbonato", Polímeros Vol.11, No. 4, pp. 213-221.

Bolkcom, C., Elias, B. and Feickert, A., 2003, "Homeland Security: Protecting airlines from terrorist missiles", Congressional Research Service Report for Congress, The Library of Congress, USA, 27 p.

Brunetaud J.M. and Hill, S., 2012, "Risks from lasers". Retrieved in July 20, 2012, from http://www3.univlille2.fr/safelase/english/ haza_en.html

Caidin, M., 1992, "Growing threat of UVR", Aviation Safety, Vol. 12, No. 3, pp.1-15.

Diffey, B. L. and Roscoe, A. H., 1990, "Exposure to solar ultraviolet radiation in flight", Aviation Space and Environmental Medicine, Vol. 61, No. 11, pp. 1032-1035.

Elbyt Systems, 1999, "Sensor and electro-optics solutions. MUSIC". Retrieved in July 04, 2013, from http://www.elbitsystems-us.com/ sensor-electro-optics-solutions/airborne-maritime/survivability/music

GlobalSecurity.org, 2011, "AN-AAQ-24 Directional Infrared Countermeasures (DIRCM)". Retrieved in May 31, 2012, from http://www.globalsecurity.org/military /systems/aircraft/systems/ an-aaq-24.htm

Hudson, R.D., 1969, "Infrared system engineering", New York: John Wiley \& Sons, USA, $642 \mathrm{p}$.

Laurenzo, R., 2005, "Antimissile systems for airliners". Aerospace America: American Institute of Aeronautics and Astronautics, Vol. 43, Ed. 3, pp. 33-37.
Lelek, M., 2007, "Laser and non-linear optics - Laser safety". Retrieved in January 15, 2012, from http://www.optique-ingenieur. org/en/courses/OPI_ang_MO1_CO2

Nakagawara, V. B. and Montgomery, R. W., 2008, "Infrared radiation transmittance and pilot vision through civilian aircraft windscreens", Federal Aviation Administration, (DOT/FAA/AM-08/15), 18 pp.

NASA, 1998, "Ask an Astrophysicist". Retrieved in July 20, 2012, from http://imagine.gsfc.nasa.gov/docs/ask_astro/answers/ 980119b.html

Northwestern University, 2011, "Laser Safety Handbook", 20pp. Retrieved in July 19, 2012, from http://www. research. northwestern. edu/ors/forms/laser-safety-handbook.pdf

Seeber, F., 2012, "Fundamentals of Photonics", Module 1.2 - Light Sources and Laser Safety, Retrieved in July 19, 2012, from http://spie. org/Documents/Publications/00\%20STEP\%20Module\%2002.pdf

Setlow, R.B., 2003, "The hazards of space travel". Retrieved in July 20, 2012, from http://www.nature.com/embor/journal/v4/n11/ full/embor7400016.html

West, S.K., Duncan, D.D., Munoz, B., Rubin, G.S., Fried, L.P., Bandeen-Roche, K. and Schein, O.D.,1998, "Sunlight exposure and risk of lens opacities in a population-based study: the Salisbury Eye Evaluation project". The Journal of the American Medical Association, Vol. 280, No. 8, pp. 714-718.

Wisegeek, 1999, "How Dangerous is UV Radiation?". Retrieved in July 20, 2012, from http://www.wisegeek.com/how-dangerous-isuv-radiation.htm 